\title{
¿QUIÉN LE TEME A LA IGUALDAD? ${ }^{1}$
}

\author{
Marcelo Alegre \\ Universidad de Buenos Aires- Sociedad Argentina de Análisis Filosófico
}

RESUMEN. El igualitarismo enfrenta objeciones en los tres planos de la filosofía política y moral, (el de las virtudes, el de las consecuencias, y el de los deberes). Las pincipales críticas de que se ocupa este trabajo son la de la la Nivelación Hacia Abajo, la de las Libertades y la de la Envidia. Mi perspectiva se distingue de otras defensas igualitarias porque en lugar de reconocer y minimizar esos efectos, no admite que el igualitarismo implique nivelar para abajo, o vulnerar la libertad, o que sea una mera racionalización de la envidia, Una reconstrucción adecuada del ideal de la igualdad nos permite identificar los errores de los críticos.

\begin{abstract}
Egalitarianism faces objections on all three levels of moral and political philosophy: virtues, consequences, and duties. The main criticisms analyzed here are the Leveling Down Objection, the Freedom Objection and the Envy Objection. I depart from other viewpoints in that I do not concede, as many egalitarians do, that equality implies leveling down, or trumping on liberty, or rationalizing envy (egalitarians minimize those effects in different ways). A plausible reconstruction of the ideal of equality shows the mistakes of its critics.
\end{abstract}

\footnotetext{
${ }^{1}$ Agradezco a Carlos Véliz por ayudarme a traducir el tercer capítulo de mi disertación doctoral (NYU, 2003), parte del cual, con muchas modificaciones, integra este trabajo. Thomas Nagel, Ronald Dworkin y Carlos Rosenkrantz leyeron y comentaron varias veces versiones anteriores de este ensayo, así como Yochai Benkler, Mattias Kumm, y mis compañeros del programa doctoral en NYU. Agradezco a Roberto Gargarella, Marcelo Ferrante, Eduardo Rivera López y Horacio Spector por observaciones a un borrador que presenté en la Universidad Di Tella en 2003, parte del cual está integrado a la sección 5 y también a los asistentes al Coloquio "Derecho, Moral, y Política”, de la Facultad de Derecho de la Universidad de Palermo, especialmente Raquel Asensio, Romina Faerman, Carolina Fairstein, Gustavo Maurino, Florencia Luna, y Carlos Starmanns. Sin embargo, nadie más que yo, claro, debe responder por los errores remanentes.
} 


\section{Introducción}

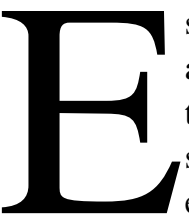

ste trabajo se ocupa de las principales objeciones sustantivas ${ }^{2}$ al igualitarismo. Las objeciones que describiré operan en los tres planos de la teoría moral: el plano de los deberes, a los que se refiere el enfoque deontológico, el de las consecuencias, en el que se centra el consecuencialismo, y el nivel del carácter personal, que es el foco de la ética de la virtud. Ellas son la objeción de la “nivelación hacia abajo”, la objeción “de la libertad”, y la objeción “de la envidia”. Estas objeciones pueden ser respondidas de diversas formas, y en particular la primera, lo ha sido siguiendo una estrategia de "doblar la apuesta”, aceptando que la igualdad implica nivelar hacia abajo (empeorando la situación de algunos sin mejorar la situación de nadie), pero negando que ello sea un defecto fatal del igualitarismo. Esa estrategia, a mi juicio, es equivocada. El tema dominante en mi argumento es que las críticas bajo examen se basan en una visión distorsionada del ideal de la igualdad. Por lo tanto, en vez de negar la premisa subyacente a las críticas al igualitarismo de que nivelar para abajo (o violar la libertad, o manifestar envidia) es algo moralmente cuestionable, pondré de relieve que la igualdad, como ideal, no requiere, y ni siquiera acepta, cursos de acción de nivelación hacia abajo, o que vulneren libertades, o que puedan entenderse como conductas envidiosas.

Esta es la estructura de mi exposición: En la sección 2 explico qué entenderé por igualitarismo y caracterizo las principales corrientes igualitarias de raíz liberal-democrática. En la sección 3 expongo las críticas que serán objeto de mi análisis y defiendo la necesidad de defender al igualitarismo en los tres niveles del discurso normativo que referí al comienzo. En la sección 4 trato la objeción de la "nivelación hacia abajo". Luego de describir qué tipo de casos pueden ser genuinamente entendidos como casos de nivelación hacia abajo, sostengo que la igualdad no cae presa de esta objeción, para lo cual confronto varias afirmaciones de Larry Temkin y descalifico una supuesta versión de la igualdad, la igualdad "télica” por irrelevante en términos históricos e inaceptable moralmente. Esta sección termina con una especulación acerca de uno de los posibles motivos que podrían haber llevado a algunos a creer que la igualdad implica nivelar hacia abajo. En la sección 5, analizo la crítica según la cual el igualitarismo es incompatible con la libertad, la cual entenderé como el conjunto de derechos constitucionales de la democracia moderna. Luego de hacer notar el fracaso de la famosa

\footnotetext{
${ }^{2}$ He intentado responder a objeciones de índole formal (que la noción de igualdad es vacía, trivial y que genera confusión) en otro ensayo, “Igualdad y Discurso Moral”, Isonomía, 2005.
} 
predicción de Hayek acerca de que los estados de bienestar desembocarían en estados totalitarios, me detengo en la que creo es una fuente genuina de tensiones entre la igualdad y la libertad. Me refiero al objetivo de neutralizar las diferencias en habilidades innatas de las personas en el ámbito económico. Tras mostrar la forma en que dos de las principales teorías igualitarias resuelven el problema, propongo un camino diferente: una conciliación del argumento de la "lotería natural" con la posibilidad de tolerar cierto rango de retribuciones diferenciales en base a los talentos. En la sección 6 respondo las objeciones al igualitarismo según las cuales la igualdad es meramente una racionalización de la envidia, y que las políticas igualitarias causan un crecimiento de las propensiones envidiosas. Sugiero que la primera de estas críticas es parasitaria de la de la nivelación hacia abajo y debe ser rechazada junto con ella. Respecto de la segunda, afirmo que se basa en el viejo malentendido según el cual la igualdad se reduce a uniformidad. En la sección 6 expongo las conclusiones, formulo una observación sobre la disputa monismo-pluralismo y solicito, finalmente, la absolución de mi defendida.

\section{Un ideal bajo sospecha}

Por "igualitarismo" entenderé el haz de teorías de filosofía moral y política que comparten, en primer lugar, la creencia en la igualdad moral básica de las personas y en segundo lugar, la convicción de que dicha igualdad básica requiere una igualación (más o menos radical, según los casos) de las oportunidades, recursos, ventajas, y costos que las instituciones sociales asignan a los individuos. La primera creencia no es distintiva del igualitarismo, ya que es compartida por todas las concepciones filosóficopolíticas no discriminatorias y, consecuentemente, solamente es negada por las visiones racistas, sexistas y aristocráticas. Lo típicamente igualitario es la noción de que dicha igualdad básica requiere además de las protecciones habituales contra las prácticas discriminatorias por razones de raza, género, o proveniencia étnica, que las instituciones sociales se organicen y funcionen asignando a todos iguales posibilidades de acceso a las ventajas de la vida en común.

La conexión entre ambas creencias asume diversas formas, dependiendo de las diversas variantes de igualitarismo. Cabe mencionar al menos las siguientes dos variantes. Por un lado, hay quienes creen que la igualdad moral básica o fundamental entre los seres humanos requiere que se nos coloque en una posición de igualdad frente a las contingencias que afectan nuestro futuro, incluyendo contingencias en nuestro contexto familiar, nuestra carga genética, nuestras capacidades para atraer recursos en el mercado, etc. Diversos autores discrepan acerca de cuántas contingencias deben estar sujetas a esta política de igualación, y también discrepan respecto de si ciertos 
factores que inciden en nuestro éxito en la vida, como el esfuerzo, deben ser tratados como parte de las circunstancias azarosas -y por consiguiente estar sujetos a neutralización- o como fluyendo de nuestras decisiones $-\mathrm{y}$ por lo tanto como factores que pueden producir desigualdades aceptables-. La equiparación de recursos, según esta visión, viene a evitar que las personas queden cautivas de la suerte en lugar de poder forjar sus propios destinos a través de sus decisiones voluntarias.

Una segunda variante igualitaria afirma, en cambio, que la igualación de recursos es requerida por aquella igualdad fundamental, pero por una razón distinta: aquella igualdad básica entre las personas se vería comprometida por el tipo de relaciones de subordinación, humillación, servidumbre, etc, que se generan en situaciones de desigualdad material. De acuerdo con esta concepción, pues, las desigualdades económicas deben limitarse con el propósito de que las personas no queden en las manos de otras, a quienes deben servir para subsistir, o frente a las cuales deben implorar por asistencia. ${ }^{3}$

En este punto, cabe observar dos coincidencias importantes entre estos enfoques. Ambos coinciden, primero, en asignar a la igualdad económica una importancia meramente instrumental. La igualdad en la posesión de recursos no es valorada en sí misma, como algo valioso per se. Antes bien, es necesaria para no vulnerar la igualdad moral básica o fundamental de las personas. La vulneración se produciría, según el primer grupo de igualitarios, si las instituciones replicaran o legitimaran la buena suerte de quienes nacen en cuna de oro, o con capacidades innatas de las que otros carecen, etc. Por lo tanto, las desigualdades resultantes una vez que estos factores son neutralizados, o una vez que las personas son provistas de iguales recursos para hacerles frente, no son moralmente problemáticas (salvo ciertos extremos, que suelen resolverse a través de consideraciones paternalistas, a fin de que, por ejemplo, el arriesgado amante de los deportes extremos que no

\footnotetext{
${ }^{3}$ Ronald Dworkin, Eric Rakowski, Philippe Van Parijs ejemplifican el primer modelo, el de la igualdad "de opciones". Ver Ronald Dworkin, Sovereign Virtue, The Theory and Practice of Equality, Cambridge: Harvard University Press, 2000, en adelante "SV”, Eric Rakowski, Equal Justice, Clarendon: Oxford University Press, 1991, Philippe Van Parijs, Real Freedom For All. What (if Anything) Can Justify Capitalism, Oxford University Press, 1995. Elizabeth Anderson y Samuel Scheffler han defendido una visión "relacional” de la igualdad. Ver, Elizabeth Anderson, "What is the Point of Equality?", Ethics, Vol. 109:2, January 1999, Samuel Scheffler, "What is Egalitarianism?", Philosophy and Public Affairs 31, no.1, pp. 5-39. Rawls parece combinar ambas perspectivas. Ver, John Rawls, A Theory of Justice, Revised Edition, Cambridge: Harvard University Press, 1999. Por mi parte, he tratado de disolver las supuestas tensiones entre ambas posturas, enfatizando que la igualdad requiere mantener bajo control las disparidades económicas (aun las que la primer perspectiva observa con indiferencia, pero no solamente por las razones que preocupan a los partidarios de la igualdad relacional). "Egalitarian Rights and Constitutional Democracy”, disertación doctoral, noviembre de 2003 (New York University School of Law).
} 
tomó precauciones ni contrató un seguro médico, reciba atención médica si sufre un accidente). Pero si alguien decide valorar más su ocio que los demás, esta perspectiva de la igualdad no requiere que se transfieran recursos a su favor, cuando, con el paso del tiempo, esta persona se vea con menos recursos a su disposición que los que disfrutan personas más laboriosas. Según el segundo grupo de igualitarios, se vulneraría la igualdad moral de las personas si se permitiera que la distribución de recursos económicos (inclusive a través del mercado) produjera tal disparidad en la posesión de bienes que ciertas personas y grupos se vieran sometidos a relaciones y modos de vida indignos. Pero si las desigualdades materiales no redundaran en un deterioro de la calidad de las relaciones sociales, serían incuestionables desde esta concepción (por supuesto, esta desconexión entre desigualdades económicas y socio-políticas es, para la mayoría de los igualitarios, imposible en la práctica).

Una segunda coincidencia es que ambas perspectivas fusionan el ideal de la igualdad con el ideal de la autonomía. La primera perspectiva, la de la igualdad "de opciones" requiere que se igualen recursos y oportunidades para que pueda operar una autonomía genuina, no contaminada por factores azarosos y arbitrarios. La segunda perspectiva, la de la igualdad "relacional", también concibe a la igualdad de recursos como un reaseguro para el imperio de la autonomía: debemos ser iguales materialmente para ser autónomos y no quedar, por el contrario, a merced de quienes tienen más recursos.

No pretendo que se tome a las corrientes igualitarias precedentes como las mejores, más razonables o más aceptadas. Existen otras variantes igualitarias, e incluso las que describí admiten combinaciones entre sí. Pero las que escogí tienen en común que constituyen un blanco válido para las objeciones al igualitarismo que voy a considerar. No son creaciones excéntricas que escapan a las críticas usuales a la igualdad al precio de la irrelevancia práctica. Por el contrario, cualquiera de estas variantes defiende el tipo de políticas que los adversarios de la igualdad cuestionan, políticas que como mínimo incluyen: alta progresividad impositiva, acciones afirmativas para compensar desigualdades estructurales y heredadas, limitaciones al derecho de propiedad, amplios programas de seguros social y médico, garantías de ingresos mínimos, y una fuerte presencia estatal en la enseñanza. Por cierto, mi respuesta a alguna de las críticas sí habrá de afirmar que éstas están dirigidas a una caricatura de la igualdad, o a una deformación de este ideal. Pero así como creo que la descripción del igualitarismo subyacente a estas críticas no se ajusta a las versiones que he descripto, pienso que tampoco reconstruye de manera mínimamente aceptable el ideario de ningún movimiento político-social significativo. 


\section{Consecuencias, restricciones deontológicas, y virtudes. Tipología del anti-igualitarismo}

El igualitarismo ha sido sometido a objeciones en los tres principales niveles de análisis de la filosofía moral: el de las consecuencias, el de las restricciones deontológicas, y el de las virtudes. Así, los anti-igualitarios consecuencialistas afirman que el estado de cosas que el igualitarismo produce es peor que al menos algunas de las alternativas no-igualitarias (que la igualdad compromete la eficiencia resulta un lugar común del discurso conservador). A su vez, para los anti-igualitarios dentológicos, seguir los consejos igualitarios implica violar algunas restricciones no-consecuencialistas, principalmente, en la forma de derechos y títulos legítimos. En términos más corrientes, el igualitarismo es acusado de hacer peligrar la libertad y otras garantías de una sociedad abierta. Finalmente, algunos autores atacan al igualitarismo desde la perspectiva de la ética de la virtud. Una persona virtuosa, de acuerdo a esta visión, no puede ser igualitaria.

A mi juicio, las tres mayores objeciones a las teorías de la igualdad son: i) El Argumento de la Nivelación para Abajo; ii) El Argumento de las Libertades y iii) El Argumento de la Envidia. El argumento de la Nivelación asume una estructura consecuencialista, pero también deontológica. Es consecuencialista en cuanto está ligado a la idea de que la igualdad puede impedir el logro de estados de cosas mejores, o que conspira contra la maximización de algún valor, como el bienestar agregado, la felicidad, o la riqueza. Es deontológica en cuanto acusa al igualitarismo de propender o permitir la destrucción de bienes de los que tienen más para "nivelarlos” con los que tienen menos. El argumento de las libertades, que critica el carácter autoritario del ideal igualitario (o al menos de parte de ese ideal) es típicamente deontológico. Un ejemplo es la famosa estocada de Nozick contra la idea de la lotería natural, consistente en preguntarse si dicha idea no favorecería la distribución forzada de órganos corporales. El argumento de la Envidia, se mueve en el plano de las virtudes. El igualitarismo, según esta objeción, no es más que el producto (o una “racionalización”) del vicio de la envidia. Un ciudadano virtuoso, en cambio, no debería caer en comparaciones envidiosas entre lo que él posee y lo que poseen los demás.

No trataré de establecer aquí cuál de las tres aproximaciones a la teoría moral (el consecuencialismo, el deontologismo, o la ética de la virtud) resulta a mi juicio más adecuada. Sin embargo, creo que el igualitarismo puede y debe ser defendido contra los ataques provenientes desde las tres perspectivas. La razón de por qué una teoría política debe ser evaluada a través de cada una de las tres dimensiones de la práctica moral (consecuencias, deberes, virtudes) es que la deliberación democrática sería radicalmente incompleta si una de aquellas dimensiones estuviera ausente o fuera subestimada. Cual- 
quier teoría que no tome en cuenta las consecuencias sería, usando las palabras de Rawls, "irracional, loca"4. A su turno, cualquier teoría que descuide la existencia de restricciones en la persecución de objetivos podría justificar cursos de acción horrendos - un punto que resulta central para las visiones deontológicas-. Finalmente, una teoría política debe prestar atención también a la necesidad de propagar las disposiciones básicas para sostener y reforzar las conductas e instituciones públicas justas, de acuerdo a lo afirmado usualmente por los filósofos morales de la ética de la virtud. Por lo tanto el ideal de la igualdad, o para el caso, cualquier ideal, sería deliberativamente incompleto si no se manifestara en estas tres dimensiones de la justicia, y fracasaría si pudiera ser descalificado en cualquiera de ellas.

\section{El Argumento de la Nivelación hacia Abajo}

Una de las objeciones más difundidas a las propuestas igualitarias es que las políticas igualitarias colisionan con el propósito de incrementar el bienestar agregado de la sociedad. Esto puede ocurrir de distintas formas. Primero, las políticas igualitarias podrían mejorar la situación de los más desfavorecidos pero perjudicando a los que están mejor en una medida mayor que la del beneficio de los primeros. ${ }^{5}$ Es decir de una situación $(5,2)^{6}$ el igualitarismo favorecería pasar a una situación $(3,3)$. La mejora de los que están peor se ve acompañada por un deterioro en la posición de los mejor situados que es mayor que dicha mejora, y el total de recursos (o bienestar, o cualquiera sea la medida relevante que utilicemos) también cae (en este caso de 7 a 6). Segundo, las políticas igualitarias podrían favorecer un curso de acción aun más sencillo: modificar la distribución original $(5,2)$ simplemente destruyendo 3 unidades de los mejor situados, para pasar a una situación $(2,2)$. Esto es nivelar para abajo. Tercero, la nivelación para abajo puede adoptar formas aun más extremas, por ejemplo transformando $(5,2)$ en $(1,1)$, una situación en la que todos están peor que antes, pero iguales.

Los tres cursos de acción son agregativamente negativos, es decir, los tres disminuyen el total de recursos o beneficios. Pero quisiera concentrarme en los casos de nivelación hacia abajo, como el segundo y el tercero. En el primer caso la nivelación no se produce hacia abajo estrictamente, sino

\footnotetext{
${ }^{4}$ J. Rawls, A Theory of Justice, p. 30. [J. Rawls, Teoría de la Justicia, Ed. F.C.E., página 41]

${ }^{5}$ En este trabajo usaré indistintamente la idea de recursos, beneficios, utilidades, ya que para el propósito de la presente discusión no es necesario elucidar cuál teoría acerca de la moneda de cambio de la igualdad (la discusión sobre cigualdad de qué?) es la más acertada.

${ }^{6}$ La expresión entre paréntesis debe interpretarse como indicando la cantidad de bienes, recursos o unidades de utilidad que poseen dos personas o grupos. Así, $(5,2)$ significa que el o los mejor situados tienen 5 unidades, y el o los peor situados, 2.
} 
en un punto superior al punto más bajo de la distribución original. En este caso, hay algo que puede decirse en favor de la distribución operada, y es que ha beneficiado a alguien. En los casos segundo y tercero, la igualdad no beneficia a nadie (en el caso segundo nadie está mejor y alguien está peor, mientras que en el tercero todos terminan en peor situación). El primer curso de acción, pues, no da lugar a la objeción de nivelar para abajo (“ONA”, de acá en más). Sí da lugar a otra objeción, que en clave consecuencialista afirmaría que la igualdad afecta el total de bienes o riquezas del conjunto. Pero esta objeción no es tan preocupante, una vez que tomamos en cuenta que muchas restricciones a la adopción de alternativas consecuencialistas producen este resultado. No es un argumento a favor de permitir el trabajo infantil el que así aumentaría la productividad de la economía, como no es un argumento válido a favor de la tortura policial el que tal vez así se esclarecerían más delitos. Del mismo modo, la razón por la que la discriminación de las mujeres debe ser combatida no es que el paso de una sociedad sexista a una donde impere la igualdad de géneros creará más felicidad en las mujeres que frustración en los hombres. El caso de la distribución de beneficios y costos económicos asume la misma estructura: resulta plausible afirmar que el mejoramiento de la situación de los que están peor, aun a costa de un sacrificio mayor de los mejor situados, es una política que unos y otros escogerían bajo condiciones de imparcialidad. Esta es la estrategia preferida por los igualitarios $\mathrm{y}$, aunque puede ser equivocada, lo que es importante destacar es que resulta razonable, es decir, que el mero señalamiento de que la igualdad afecta la cantidad total de recursos o beneficios disponibles no constituye un argumento letal o descalificante contra el igualitarismo. Después de todo, hasta el libertarismo de Nozick puede resultar el blanco de la crítica consecuencialista, si ésta pudiera mostrar que algunas de las restricciones deontológicas de la teoría libertarista dificultan la maximización de la riqueza o el bienestar.

Ocupémonos pues de la nivelación para abajo. Una exposición bastante gráfica de la nivelación para abajo es la desplegada en el cuento "Harrison Bergeron”, de Kurt Vonnegut JR.7 Ocurre en 2081, época en la que "todos eran, finalmente, iguales... en todo.” Por ejemplo, a la gente con índices de inteligencia por encima del promedio se le requería por ley usar un mecanismo en la cabeza que producía un ruido agudo cada veinte segundos, como modo de disuadirlos “de aprovechar injustamente de su ventaja cerebral.” De modo similar, la familia que protagoniza la historia mira por televisión a unas bellas y ágiles bailarinas obligadas a utilizar máscaras y a llevar

\footnotetext{
${ }^{7}$ Kurt Vonnegut JR, “Harrison Bergeron”, in Brian W. Aldiss and Harry Harrison (Eds.) Decade The 1960s, pp. 34-40.
} 
ridículos contrapesos en sus cuerpos para neutralizar su encanto y rapidez. Estos dispositivos eran orwellianamente controlados por control remoto por una "Incapacitadora General", de modo de asegurar que "nadie fuera... más inteligente...elegante... más fuerte o más ligero que nadie".

Hasta el momento la respuesta dominante de los igualitarios frente a esta objeción ha sido la de doblar la apuesta. Larry Temkin, por ejemplo, ha defendido la idea de que la igualdad puede favorecer la nivelación para abajo, pero que eso no es un problema letal para el igualitarismo. ${ }^{9}$ Del mismo modo, Derek Parfit, en su importante trabajo sobre las variedades de igualitarismo, ha dicho que la ONA reposa en presupuestos equivocados. ${ }^{10}$ Luego de analizar estas posiciones, voy a proponer una respuesta diferente, según la cual, la igualdad no implica ni favorece la nivelación para abajo.

Los objetores asumen el siguiente razonamiento:

1. El igualitarismo implica o acepta nivelar para abajo.

2. Nivelar para abajo es incorrecto moralmente.

3 (Conclusión) El valor de la igualdad debe, por lo tanto, ser abandonado.

Según algunos igualitarios la ONA debe ser respondida negando la segunda premisa, es decir, negando que la nivelación para abajo esté mal en todos los casos, o afirmando que dicho curso de acción mejora la situación en un cierto aspecto, aunque esta mejora pueda ser neutralizada por otras consideraciones. Para volver al ejemplo original, -en que A dispone originalmente de 5 unidades de recursos o de utilidad y B, de 2- nivelar para abajo dejaría a ambos con 2 unidades. ¿Cómo podría justificarse esta nivelación hacia abajo, siendo que el empeoramiento de A no tiene ningún impacto en $\mathrm{B}$ ? Los igualitarios como Temkin piensan que, por más contraintuitivo que parezca, la movida implica una cierta mejora moral. Esta mejora puede ser concluyente, de modo que la nueva distribución sea preferible a la original, o apenas una mejora prima facie, es decir que la nueva distribución es preferible en algún aspecto a la original, aunque tal vez por otras razones, debamos preferir, considerando todas las razones, la distribución original. O sea que, de acuerdo a esta línea de razonamiento, la segunda premisa de la ONA debe

\footnotetext{
8 "Harrison..." p. 34.

${ }^{9}$ Larry S. Temkin, "Harmful Goods, Harmless Bads", en Raymond G. Frey y Christopher Morris (Eds.), Value, Welfare, and Morality, Cambridge University Press, 1993, pp. 290-324, Inequality, Oxford University Press, Paperback ed., 1996, "Equality, Priority, and the Levelling Down Objection”, en The Ideal of Equality, Matthew Clayton y Andrew Williams, (Eds.) MacMillan Press, 2000, “Equality, Priority or What?”, Economics and Philosophy, 19 (2003) 61-87.

${ }^{10}$ Derek Parfit, “Equality or Priority?” en Clayton y Williams, The Ideal of Equality, MacMillan Press, 2000, pp. 81-125.
} 
ser rechazada, porque cuando se alcanza una igualdad a través de nivelar para abajo, la situación mejora, sea en algún aspecto o concluyentemente. ${ }^{11}$

Deseo responder a la ONA de manera diferente, negando la primera premisa, y aceptando la segunda. Es decir, rechazaré la idea de que la igualdad exige nivelar para abajo. A mi juicio, no lo exige, y más aún, no lo acepta. Para demostrar esto, primero distinguiré casos puros e impuros de la nivelación abajo, escrutaré el tipo de igualitarismo que los objetores que se basan en el argumento de la nivelación hacia abajo tienen en mente, explicaré por qué esa concepción supuestamente igualitaria no lo es, mostraré por qué la versión más plausible de igualitarismo no es presa de esta objeción. Luego arriesgaré una explicación acerca de las razones que pueden motivar a los objetores a recaer en el error de adjudicar al igualitarismo la falla de aceptar o propender a la nivelación para abajo.

\subsection{Casos puros e impuros de nivelación hacia abajo}

Es necesario aclarar, como señala Parfit, que ciertas situaciones que aparecen como instancias de nivelación hacia abajo no lo son. Por ejemplo, piénsese en una sociedad donde rige el voto calificado, y los universitarios tienen doble voto. Si esa sociedad eliminara este privilegio, y consecuentemente todos los ciudadanos dispusieran de un voto, ésta no sería una instancia genuina de nivelación para abajo. La razón es que existen otras dimensiones en las que el cambio impacta positivamente. Aquellos que durante la vigencia del voto calificado no accedían al voto doble, ahora se encuentran mejor en términos de poder político. Por lo tanto, si bien ahora los universitarios tienen menos votos, esta disminución está acompañada por una mejora para otros, y para la sociedad en su conjunto.

Para que la nivelación sea genuinamente "para abajo” y, por lo tanto, problemática moralmente, no debe producir efectos positivos de ningún tipo. Si el análisis de la nivelación para abajo no filtrara los casos impuros, la objeción perdería toda su fuerza. Los casos puros de nivelación hacia abajo, pues, son aquellos en los que los que están mejor pasan a ocupar la misma posición que los que están peor, sin ninguna mejora en la situación de los últimos.

\section{2. ¿Exige la igualdad nivelar para abajo?}

El filtro aplicado en la sección anterior no es meramente teórico. De hecho, mediante él quedan fuera de la escena una buena parte de las políticas igualitarias. Muchos cursos de acción igualitarios implican nivelar en

\footnotetext{
${ }^{11}$ Christopher Ake, “Justice as Equality”, Philosophy and Public Affairs 5 (1975) 69-89.
} 
alguna dimensión pero para mejorar la situación de los que están peor (o del conjunto) en otra dimensión. En verdad, cuesta imaginar situaciones en las que en nombre de la igualdad estaría justificado empeorar la situación de algunos sin que ello beneficiara a nadie. Derek Parfit y Larry Temkin, sin embargo, afirman que hay un tipo de igualitarismo que sí exige nivelar para abajo. Parfit lo llama igualitarismo télico (o teleológico), y Temkin, igualitarismo no instrumental. Los igualitarios télicos o no instrumentales valoran la igualdad en la posesión de recursos o de beneficios en sí misma, sin preocuparse por el impacto que dicha igualdad tiene en el bienestar de las personas, o en el funcionamiento de las instituciones sociales.

Por el contrario, los igualitarios deónticos (o deontológicos), o instrumentales, valoran la igualdad en la distribución de bienes o recursos como un requisito del funcionamiento justo del estado, o como una condición exigida por otras consideraciones. La idea es que un estado debe tender a la igualdad económica para evitar actuar de manera discriminatoria, o para lograr una convivencia armónica, etc. La mera posesión de recursos iguales entre las personas no es valorada en sí misma. Correlativamente, las desigualdades que no pueden rectificarse no son injustas. Por citar un ejemplo de Parfit, la desigualdad entre el tipo de vidas que disfrutamos en la actualidad y las vidas de los seres humanos en la edad de piedra resulta problemática para el igualitarismo télico, pero no para un igualitario deóntico o instrumental: si no hay nada que podamos hacer para rectificar esa disparidad, o si nada bueno podría obtenerse rectificándola (si fuera posible hacerlo), entonces esa desigualdad es solamente fáctica, no moral.

Para los igualitarios deónticos o instrumentales, la mera disparidad en la posesión de bienes o recursos es tan irrelevante moralmente como la desigualdad en la estatura o en el peso. Las únicas desigualdades moralmente relevantes, y que por lo tanto la igualdad como valor moral exige neutralizar de algún modo, son aquellas que denotan una política discriminatoria o relegan a algunos en el disfrute de beneficios. Para volver al ejemplo de la estatura o el peso, que algunas personas sean más altas o más voluminosas que otras no es motivo de preocupación moral. Ahora bien, que algunas personas se vean en dificultades para acceder al transporte público por su peso o su altura sí es una desigualdad moralmente relevante, y el diseño institucional debe evitar que algunos se vean en desventaja por la mera posesión de estos rasgos. Un igualitario télico, en cambio, ve razones para lamentar el mismo hecho de la diferencia en contextura física entre las personas. Piénsese en el caso de la ceguera. Los anti-igualitarios afirman que el valor de la igualdad exige (o al menos autoriza) que se privara de la vista a los que pueden ver, de modo que todos resultaran igualmente ciegos. El propio Temkin afirma: 
"Un anti-igualitario podría incrédulamente preguntarme ¿realmente creo que hay algún aspecto en el que un mundo en el que algunos son ciegos es peor que uno en el que todos lo son? Sí. ¿ Significa ésto que sería mejor si le quitásemos la vista a todos? No. La igualdad no es lo único que importa. Pero importa.”

Temkin justifica su posición a través de estas preguntas:

“¿No es injusto que algunos estén peor que otros sin que medie culpa de su parte? ¿ंNo es injusto que algunos sean ciegos, mientras otros no? ¿ No es mala la injusticia?”12

Un igualitario deóntico o instrumental respondería rápidamente: No, no es injusto que algunos sean ciegos y otros no. Es desafortunado que algunos sean ciegos, pero no injusto. No es la obra de nadie, ni el resultado de una política pública, de modo que no puede ser injusto. Podría haber algún aspecto en el que una sociedad donde todos son ciegos sea mejor que una en la que solo algunos fueran ciegos, si esta disparidad diera lugar a explotación, o humillaciones (si, por ejemplo, los videntes esclavizaran o martirizaran a los ciegos). Pero en ausencia de este tipo de efectos, una situación en la que todos fueran ciegos sería peor, bajo cualquier aspecto.

Para Temkin, la ONA presupone una idea equivocada que él llama El Eslogan, según la cual "Una situación no puede ser mejor (o peor) que otra bajo ningún aspecto si no es mejor (o peor) para nadie en particular”. ${ }^{13}$ Parfit, de manera similar, afirma que la ONA presupone una idea, la idea de la afectación personal [Person-Affecting Claim], que él no encuentra convincente. Ahora bien, como para Temkin hay varios casos que desmienten la plausibilidad del Eslogan, éste debe ser abandonado. Una vez que nos deshicimos del Eslogan, concluye Temkin, ya no quedan motivos para aceptar la ONA. Temkin se apoya, entre otros, en el caso de la justicia retributiva. Según él, la justicia exige que los genocidas terminen en una situación peor que la de los santos, aunque ese castigo no beneficie a nadie (porque, por ejemplo, nadie se entera de la imposición del castigo). En este caso, la situación en la que se hace justicia es mejor que la situación en que rige la impunidad, aunque no hay nadie para quien la situación justa es mejor. Temkin concluye, pues, que el Eslogan debe ser rechazado, y, con él, la ONA.

No comparto este punto de vista. Lo que Temkin llama el Eslogan no es a mi juicio, una ley de la física, tal que si, por ejemplo, uno encontrara un metal que no se expande al calor, entonces la ley según la cual los metales se expanden al calor perdería validez. El Eslogan es algo diferente, es un principio moral de índole general, que puede admitir excepciones, siempre que estén fundadas en razones suficientemente atractivas. En ausencia

\footnotetext{
${ }^{12}$ Temkin, “Equality...”, p. 155.

${ }^{13}$ Temkin, “Equality...”, p. 136.
} 
de estas razones, opera el principio general. La idea de que está mal o es incorrecto perjudicar a alguien sin que medie beneficio alguno para nadie, es un principio general que, a menos que tengamos otras razones de peso suficiente, debe gobernar nuestras acciones, y las del estado. Puede haber razones de diferente tipo para que el principio ceda. Tal vez el castigo por las acciones incorrectas provea una razón plausible (digo “tal vez”, porque hay gente razonable que cree, precisamente, que cuando el castigo no trae ningún efecto benigno, no está justificado). Pero aun si aceptamos la noción retribucionista que Temkin defiende, ella solamente proveería una excepción al principio general. Este caso nos brindaría una razón impersonal para dejar de lado el Eslogan, el cual, por definición asume una perspectiva personal del valor. Por cierto, podemos imaginar infinidad de casos en los que una situación es mejor que otra sin que sea mejor para nadie en particular, si creemos en la validez de valores impersonales. Podríamos pensar, por ejemplo, que un mundo igual que el actual pero sin los glaciares de la Patagonia (o sin los osos panda, o sin Las Meninas) sería un mundo peor, aun si nadie se enterara de su falta. Pero el punto que interesa para nuestra discusión es si la igualdad télica revista entre ese tipo de valores impersonales, tal que nos autorice a pensar que una situación de igualdad es mejor que otra sin que sea mejor para nadie. Lo que un defensor de la igualdad télica debe mostrar es que cuando se nivela para abajo se enaltece un valor o se alcanza un beneficio o mejora que debe balancearse contra el mal que se impone a los que sufren la nivelación. En otras palabras, que existan excepciones plausibles al principio general de que nada puede ser bueno si no es bueno para alguien, no implica que el principio sea inválido, ni que cualquier excepción sea admisible.

Pensemos en un caso paralelo, el principio moral que veda mentir. Este principio no es absoluto (salvo para Kant, claro). Podemos imaginar infinidad de excepciones al principio: mentiras piadosas, mentiras que evitan grandes daños, mentiras para engañar a una persona que busca a alguien para matar/violar/robar, etc, etc. Pero esto, con seguridad, no significa que el principio deba ser abandonado. Cada vez que pretendamos mentir con impunidad moral deberemos basarnos en alguna excepción plausible. Pero estaríamos haciendo trampa si, por ejemplo, mintiéramos en nuestra declaración de impuestos porque está justificado mentir para salvar a un inocente, o para confortar a un moribundo. Del mismo modo, el igualitario télico no puede aprovecharse sin más de la existencia de otras excepciones al principio subyacente al Eslogan. ${ }^{14}$

14 Temkin concluye su análisis de la ONA afirmando que la igualdad conduce a veces a resultados indeseables. Pero como lo mismo sucede con otros valores, como la autonomía o la 
Si solamente la variante teleológica del igualitarismo cae presa de la ONA, cabe que nos preguntemos qué es lo que puede aducirse en favor de esta postura. Por mi parte, creo que es una monstruosa criatura de laboratorio, sin ninguna conexión con el igualitarismo que conocemos. Para volver al ejemplo de Parfit, el igualitario télico lamenta la desigualdad entre el nivel de vida de los seres humanos en la edad de piedra y en el presente. Como resulta imposible mejorar el estándar de vida de los muertos, se sigue que para el igualitarista télico habría algo bueno en un eventual empobrecimiento radical de la generación actual, que nos llevara a vivir con las comodidades propias de la edad de piedra. Ni los movimientos en favor de la igualdad de género, ni las luchas en contra del racismo, ni los esfuerzos en contra de la pobreza global (por citar experiencias igualitarias del pasado y del presente) han reposado en la extraña idea de que la igualdad podía alcanzarse nivelando para abajo, es decir, negando el voto a los blancos y a los negros, o a los varones $y$ a las mujeres, o empobreciendo drásticamente a toda la humanidad por igual. Por el contrario, un elemento definitorio del igualitarismo es su preocupación por el sufrimiento y la postergación que las desigualdades producen en sus víctimas. La razón decisiva en contra del igualitarismo télico es su absoluta indiferencia por la situación de los que están peor. Lo que motiva el rechazo por parte del genuino igualitarismo de las desigualdades en la distribución de cargas y beneficios sociales es que éstas son incompatibles con la igual dignidad de las personas, ya que equivalen a valorar más el éxito en la vida de unos que el de otros. Esta idea de igualdad nunca puede llevarse a cabo empeorando la suerte de algunos sin ningún beneficio para otros.

Se esgrime, en defensa del igualitarismo télico, que en los casos de nivelación hacia abajo hay un aspecto en que la situación es mejor, ya que hay igualdad. Pero este argumento no parece razonable. En el contexto de una deliberación honesta, no es más que una afirmación opaca, que no nos dice nada significativo. Si se refiere a que luego de la nivelación para abajo las personas relevantes tienen lo mismo, eso no es una contribución. Eso ya lo sabíamos. Si se nos quiere convencer de que eso es valioso, la simple repetición de que eso encarna el valor de la igualdad no puede satisfacernos.

Por último, resulta obvio que el igualitarismo télico resulta estructuralmente inaceptable para quienes rechazan la visión teleológica del valor, es decir para quienes se niegan a subordinar lo justo o correcto a lo que es

utilidad, esto solamente demuestra, según él, que la moral es pluralista. Ahora bien, si el hecho de que un estándar moral lleve a veces a resultados inaceptables no descalifica, por sí, a dicho estándar, ¿por qué cree Temkin que las excepciones al Eslogan sí lo descalifican? 
bueno, según las palabras de Rawls. ${ }^{15}$ (Como vimos, el igualitarismo télico no nos dice ni siquiera qué hay de bueno en la igualdad télica, como la que podría darse entre personas que viven en épocas o planetas distantes). Considerar a esta posición como el verdadero igualitarismo sería una arbitrariedad.

La ONA no es una objeción exitosa contra el igualitarismo. Solamente una versión académica del igualitarismo cae presa de esta objeción. Esta versión es absurda y no tiene correlato en ninguno de los discursos encarnados en las luchas pasadas y presentes por la igualdad. El igualitarismo no implica nivelar hacia abajo. Privar a algunos de ciertos beneficios sin razón alguna es incompatible con una sociedad de iguales.

\subsection{Luchar por justicia y nivelar para abajo}

¿Qué pudo provocar la confusión de creer que la igualdad implica nivelar para abajo? Tal vez el hecho de que muchas pugnas por la igualdad de derechos, como toda pugna, incluyan la amenaza de perjudicar a los poderosos aun cuando este perjuicio no beneficie a los peor situados. El éxito de muchas luchas por la justicia (pensemos en una huelga justificada) depende de efectuar amenazas creíbles, las que a su vez dependen de transmitir el mensaje de que los huelguistas y luchadores están preparados para finalizar en una posición peor (comparada con la que actualmente detentan) si no se accede a sus demandas, o el mensaje de que están dispuestos a causar un perjuicio a los patrones aun cuando no redunde en un beneficio para ellos. En ambos casos alguien terminaría peor sin que nadie termine mejor. Como en toda amenaza, por supuesto, el que amenaza prefiere no tener que cumplir con ella. Pero para eso debe lograr convencer al amenazado de que sí está dispuesto a hacerlo.

Por lo tanto, supónganse 3 escenarios:

1) Statu quo: Patrones 7, Obreros 2 (explotación y salarios miserables)

2) Lucha sin Acuerdo: Patrones 4, Obreros 1 (cierre del establecimiento)

3) Lucha y Victoria: Patrones 5, Obreros 3 (fin de la huelga, menores ganancias, mejores salarios)

Para ir de 1 a 3 , los Obreros deben estar preparados para finalizar en el escenario 2, que es un escenario en el que todos están peor y nadie está mejor. Es más, ellos deben convencer a los Patrones de que prefieren 2 a 1. Es esto lo que hace creíble su amenaza, y muchas veces ésta es la situación que termina resultando. ¿No es esto nivelar para abajo? Tal vez este tipo de diná-

${ }^{15}$ John Rawls, A Theory of Justice, Harvard University Press, 1971, p. 24. 
micas sociopolíticas lleven a los anti-igualitarios a sostener que la igualdad implica igualar para abajo, pero creo que estos son casos de igualación hacia abajo doblemente impuros. Por un lado, son impuros en cuanto los Obreros podrían afirmar que ellos en 2 están mejor, ya que es preferible estar desocupado que explotado. Pero por otro lado, y esto es lo importante, aun si ellos terminaran concluyentemente peor en 2 (de modo que los números del ejemplo tomaran en cuenta el valor en términos de dignidad de no recibir un salario infamante), esa no es la situación preferida por los Obreros. No es su primer opción. Ellos prefieren 3, que es una situación en la que no hay nivelación para abajo. Cuando la preferencia por 2 es vista como parte de una estrategia, la acusación de nivelar hacia abajo, parece infundada. A menudo, el resultado de las luchas por la igualdad, sobre todo en el plano económico, es que todos terminan peor. Pero en estos casos la nivelación para abajo no debe ser cargada a la cuenta del igualitarismo, sino de quienes resisten el avance de la igualdad.

\section{Igualdad, Libertad y Derechos}

La concepción igualitaria que estoy defendiendo, favorece la idea de la existencia de una fuerte compatibilidad entre los valores de la libertad y la igualdad. Ella niega la visión pluralista de que ambos valores no están, en el nivel más profundo, sujetos a acuerdo, ${ }^{16}$ y que en algunas ocasiones debemos escoger entre la satisfacción de las demandas de uno de estos dos valores. En cualquier caso, aun si la tesis pluralista fuerte fuese correcta, podría no resultar aplicable a la relación entre la igualdad y la libertad. Una manera de presentar el caso pluralista a favor de la incompatibilidad entre esos dos ideales podría ser expandiendo la noción de uno de aquellos valores de forma tal que el conflicto sea inevitable desde el inicio. Berlin habla, por ejemplo, de la libertad del propietario de esclavos, y de la libertad del torturador. ${ }^{17}$ Por supuesto, cualquier concepción política que admitiera el mínimo ingrediente de igualdad necesario para abolir la esclavitud o la tortura, destruiría la libertad en este sentido. Pero difícilmente se sigue de esto que lo que ha tenido lugar sea un conflicto de valores, por la simple razón de que estipular solamente que el poder del propietario de esclavos o el del torturador son libertades no es más que una decisión lingüística: podemos

${ }^{16}$ Isaiah Berlin, Four Essays on Liberty, Oxford University Press, edición de 1969, pp. xlix-lv, y pp. 167-172; “The Hedgehog and the Fox”, en Russian Thinkers, Penguin Books, 1994, pp. 22-81. [Hay versión castellana, Isaiah Berlin, Cuatro Ensayos sobre la Libertad, Ed. Alianza, y El Zorro y el Erizo,...]

${ }^{17}$ Berlin, Four Essays,en pp. lvi-lvii. Me apresuro a aclarar que utilizaré el término “pluralismo” como se lo hace en la filosofía ética. Este concepto no debe confundirse con la noción de "pluralismo" como sinónimo de tolerancia o respeto a la diversidad de opiniones. 
aceptar tal estipulación, pero entonces, debemos recordarle al pluralista que las libertades en que estamos interesados son las libertades valiosas.

Por lo tanto será más conveniente acudir a una noción moralizada de libertad. Siguiendo a Dworkin, en lugar de la idea de la libertad como un poder, ${ }^{18} \mathrm{o}$ como una licencia, ${ }^{19}$ deberíamos tratar de poner a prueba la existencia del conflicto entendiendo a la libertad como un haz de derechos ${ }^{20}$, más particularmente, como el haz de derechos civiles y políticos reconocidos y protegidos por las democracias constitucionales. Lo que perdemos en términos de rigor conceptual ${ }^{21}$ lo ganamos en términos de relevancia práctica: la auténtica cuestión en la discusión acerca del conflicto entre la igualdad y la libertad consiste en la relación entre el igualitarismo y la democracia constitucional.

¿Significa seguir un programa igualitario tomar "el camino de la servidumbre"? ${ }^{22}$ No, porque lo que motiva a los igualitarios es la esperanza de mejorar las relaciones sociales por la eliminación de situaciones opresivas o de explotación. En el corazón de este proyecto existe una poderosa creencia en la libertad. La visión se encuentra basada en el valor de la autonomía. Debido a que la autonomía tiene necesariamente un aspecto social, podemos decir que nosotros somos agentes más o menos autónomos únicamente haciendo referencia al modo con que estamos relacionados con otros. Una igual influencia o impacto en las condiciones y rasgos de las relaciones sociales es lo que hace posible la autonomía de cada una de las partes. Como podemos ver, esta lógica hace de la protección y mejora del espacio de libertad de elección individual la brújula del igualitarismo. De este modo, una sociedad ideal en términos de igualdad, sería una sociedad ideal en términos de libertad. Piénsese en una sociedad donde todos tengan un poder más o

\footnotetext{
${ }^{18}$ Hayek, The Constitution of Liberty, The University of Chicago Press, 1978 edition, pp. 11-30.

[Hay versión castellana, Los Fundamentos de la Libertad, Unión Editorial S.A., Madrid, varias ediciones]

${ }^{19}$ R. Dworkin, "What is Equality? Part III: The Place of Liberty", Iowa Law Review, 73/1:1-54.

${ }^{20}$ Dworkin, op. cit.

${ }^{21}$ Algunos de los problemas derivados del uso de este criterio pueden ser determinar cuáles son estos derechos (un problema conectado con el hecho de que existen significativas variaciones en la lista de derechos protegida por diferentes países), y el problema de los derechos no reconocidos (un libertario podría sostener que la igualdad trunca la obtención de derechos todavía no reconocidos, pero que deberían ser defendidos de todos modos).

${ }^{22}$ F. Hayek, The Road to Serfdom, The University of Chicago Press, 1994 edition. [NT: Hay versión en castellano de la edición original, F. A. von Hayek, Camino de Servidumbre, Traducido del inglés por J. Vergara Doncel; Editorial Revista de Derecho privado; Madrid, 1946]
} 
menos igual para influir en las relaciones sociales. Esa sociedad también sería una comunidad ideal en términos de libertad.

En este punto podemos ver lo que resulta errado con el argumento hayekiano en contra del igualitarismo. ${ }^{23} \mathrm{El}$ estado igualitario, dice el argumento, devendría en un enorme aparato construido con el fin de planificar cada detalle de la vida de las personas. La mera existencia de un estado tal, constituiría un peligro para la libertad, porque sería posible usar su fuerza para oprimir los derechos de los individuos. El error de este argumento de "pendiente resbaladiza" es asumir que el igualitarismo requiere de la existencia de tal monstruo burocrático. De hecho, el tipo de estado que constituye la pesadilla de los libertarios sería lo opuesto del que el igualitario propone. Un estado omnipresente, que orienta sus políticas tratando de planificar y dirigir cada curso significativo de la vida social implicaría asignar una muy desigual cantidad de poder en las manos de algunos, en violación de la premisa igualitaria de la diseminación del poder. Entonces, la Unión Soviética no es un buen ejemplo de mal igualitarismo. Por el contrario, era una sociedad profundamente inigualitaria, donde una elite monopolizaba el poder del país. La caída del Muro de Berlín fue un triunfo de la igualdad tanto como de la libertad. Y la conexión entre el capitalismo sin trabas y los derechos civiles y políticos, por otro lado, no es una conexión necesaria. Como apunta Kymlicka, los países con un capitalismo esencialmente irrestricto han tenido algunas veces pobres historiales de respeto de los derechos humanos (e.g. el mccarthismo en los Estados Unidos), mientras que países con un extenso estado de bienestar han tenido en algunas ocasiones excelentes antecedentes en la defensa de los derechos civiles y políticos (e.g. Suecia). ${ }^{24}$

$\mathrm{Y}$ a la inversa, si tratamos de imaginarnos una sociedad ideal en términos de libertad, nos encontraríamos pensando en una sociedad verdaderamente igualitaria. (Esto podría explicar por qué los países de Europa del norte son admirados tanto por los adoradores de la libertad como por los de la igualdad). El punto de Hayek acerca de la conexión entre el igualitarismo y el totalitarismo no se proponía ser sólo filosófico, sino principalmente predictivo. Sesenta años más tarde, teniendo en cuenta que los estados de bienestar europeos se encuentran entre los estados más democráticos de la Tierra, parece razonable enterrar la predicción de Hayek en el mismo cementerio donde descansan algunas de las profecías de Marx. Pero también hay una lección que extraer de esta discusión para las fuerzas progresistas, porque la

\footnotetext{
${ }^{23}$ Como es expuesta en Camino... y Los Fundamentos....

${ }^{24}$ W. Kymlicka, Contemporary Political Philosophy, 2da ed., Oxford University Press, 1999, p. 96. (Hay versión en castellano de la primera edición, Filosofía Política Contemporánea, traducción de Roberto Gargarella, Ed. Paidós).
} 
reafirmación de los derechos civiles y políticos resulta parte de la ruta a una sociedad igualitaria tanto como lo es la redistribución de recursos, un punto a menudo descuidado por las fuerzas de izquierda.

Sin embargo, hay aspectos más complicados en la relación entre igualdad y libertad. Pienso que una fuente genuina de tensiones entre estos ideales está dada por el papel de los factores innatos (centralmente los talentos) en la organización económica. Las teorías igualitarias más conocidas rechazan el hecho de que las instituciones económicas premien a los más talentosos en atraer recursos en el mercado. La idea es que el componente innato de los talentos (hay una parte importante que se debe a la educación y el entrenamiento) es un factor fortuito que no resulta un antecedente moralmente válido de las mayores retribuciones que el mercado produce en favor de los talentosos.

Rawls, por ejemplo, hizo famosa la expresión "lotería natural" en referencia al carácter azaroso de la herencia genética. Sería injusto, según Rawls, que la estructura económica habilitara la existencia de desigualdades que premiaran a las personas más talentosas. Por esa razón, no es suficiente con la garantía de un sistema amplio de libertades (establecida por el primer principio de justicia), ni con una estructura que neutralice las desigualdades de cuna y de clase (como la exigida por el principio de igualdad democrática de oportunidades). La justicia exige también, entiende Rawls, contrapesar las diferencias en talentos naturales. El principio de diferencia, entonces, está dirigido a regular estas desigualdades remanentes..$^{25}$

Esta idea del carácter fortuito de los talentos, y de la necesidad de contrabalancear los resultados de la "lotería natural", también juega un rol importante en otra prominente teoría igualitaria, la de Ronald Dworkin. ${ }^{26}$ El objetivo del esquema institucional que propone este autor está enderezado a lograr un sistema económico que sea sensible a las decisiones de las personas, e insensible a las circunstancias azarosas, entre las que figuran los talentos innatos (Dworkin se ocupa de la incidencia de otros eventos fortuitos, como las discapacidades y enfermedades, pero podemos prescindir de esa parte del análisis a los efectos de este trabajo). El punto inicial de su teoría de igualdad de recursos es una subasta hipotética de todos los

\footnotetext{
${ }^{25}$ Rawls, TJR. Mi descripción supone que todos los principios de justicia rawlsianos son igualitarios. La idea de que el primer principio es un principio de libertad y el segundo, de igualdad, no es del todo adecuada, ya que todos los principios limitan y regulan desigualdades. Ellos se diferencian por el tipo de desigualdades a que se refieren. El primer principio establece una igualdad estricta, prohibiendo desigualdades de raza, opinión, credo, conciencia, etc. El principio de igualdad de oportunidades limita las desigualdades de clase social. El principio de diferencia, por último, regula las desigualdades producto de contingencias azarosas.

${ }^{26} \mathrm{SV}$.
} 
recursos productivos, excluyendo los recursos internos (el propio cuerpo, las capacidades y talentos, etc). Posteriormente, y para diseñar una estructura que distinga entre las decisiones y el azar ["chance and choice"], Dworkin propone un esquema de seguro modelado a través de un ejercicio contrafáctico consistente en preguntarse qué protección en promedio contrataría una sociedad en la que sus miembros conocieran sus talentos pero ignoraran el retorno económico de esos talentos. Dworkin afirma que la decisión racional en esas circunstancias es la de comprar un seguro que proteja solamente contra la contingencia de no acceder a un salario modesto. De todas formas, esto resultaría en un seguro de desempleo más generoso que los conocidos en el mundo actual.

Ahora bien, tanto Rawls como Dworkin se niegan a defender una igualación absoluta de los ingresos de las personas. Rawls legitima las diferencias en ingresos en la medida que ellas favorezcan a los peor situados. La idea es que si a los más talentosos no se les permitiera recibir mayores ingresos, eso podría desalentarlos a realizar contribuciones productivas, con lo que todos terminarían peor. ${ }^{27}$ Dworkin, si bien reconoce que su seguro permitiría notables diferencias de ingresos y posición económica, entiende que las únicas alternativas que imagina son inaceptables. La primer alternativa que Dworkin descarta rápidamente es la de incluir los talentos en la subasta inicial. Si la gente pudiera comprar los talentos ajenos, y a su vez, tuviera que pujar por retener la propiedad de los talentos propios, ello conduciría, según Dworkin a la esclavitud de los talentosos. Por ejemplo, alguien con un enorme talento para la actuación cinematográfica, pero que detesta el mundo del espectáculo, podría verse imposibilitado con sus recursos iniciales para adquirir su propio talento (al menos en su totalidad) y se vería obligado a trabajar como actor de cine para que los terceros dueños de su talento puedan recuperar su inversión. Una segunda alternativa que Dworkin rechaza es la de suponer que en el sistema de seguro que él imagina, las personas elegirían una cobertura máxima, es decir, se asegurarían contra la contingencia de no percibir los ingresos más altos de la pirámide económica. La razón por la que Dworkin rechaza esta salida es, nuevamente, la esclavitud de los talentosos. El personaje del ejemplo anterior se vería obligado, ahora a través de su propia irracionalidad, a trabajar a tiempo completo en una ocupación que le repugna para poder pagar el costoso seguro que ha comprado. Su talento se habría vuelto en su contra. ${ }^{28}$

En el caso de Rawls, la oposición a una igualdad extrema de ingresos está respaldada por una noción de eficiencia: si insistiéramos en el reclamo

\footnotetext{
27 TJR.

${ }^{28} \mathrm{SV}$.
} 
de mayor igualdad económica, perjudicaríamos a todos, incluyendo obviamente a los más desaventajados. El argumento de Dworkin, en cambio, está basado en la libertad, ya que la alternativa a la igualdad moderada a que conduce su teoría es, según él, la esclavitud de los talentosos. Esta es, después de todo, una expresión más o menos sofisticada del viejo temor de que el igualitarismo lleve a una planificación y control minuciosos de la economía, incluyendo decisiones centralizadas acerca de la ocupación y la remuneración de todos los agentes económicos, ahogando la libertad de las personas de regir autónomamente el aspecto material de sus planes de vida.

Tal vez la salida a este problema sea replantear el rol de los talentos y capacidades en una teoría igualitaria. El hecho de que los talentos sean en gran medida producto del azar puede ser esgrimido contra la pretensión de que la estructura económica premie diferencialmente a los talentosos como un requerimiento de justicia. Pero que los talentosos no dispongan de un título moral a mayores riquezas no implica que deba seguirse una política de completa neutralización (o insensibilidad) a los talentos. Puede haber otras razones que militen en contra de ese curso de acción. Según creo, esta es una forma de entender la sugerencia hecha por Scheffler, según la cual el argumento de la "lotería natural" juega un rol meramente negativo en la obra de Rawls. ${ }^{29}$ De esta manera, el hecho de que el talento genere ventajas económicas podría ser tolerado, dentro de ciertos límites, particularmente que no se generen discrepancias de riquezas tan fuertes que vulneren la dignidad de las personas, o que impliquen una perpetuación de posiciones privilegiadas, o el surgimiento de castas, o distorsiones en el proceso democrático, la diversidad cultural, etc. Desde esta perspectiva, nuestro estatus como iguales no se ve afectado por el mero hecho de que otros sean más exitosos en atraer recursos, sino por el socavamiento de la autonomía que las desigualdades materiales tienden a producir cuando quedan fuera de control. El argumento de la lotería natural sirve para legitimar este control, y para contrarrestar la afirmación de que la justicia exige premiar a los talentosos con tanta riqueza como el mercado les permita acumular. Pero el argumento no obliga per se a eliminar toda diferencia en los ingresos.

Creo que hay dos visiones igualmente erróneas y relacionadas respecto de la libertad que pueden favorecer la creencia en el conflicto con la igualdad. La primera idea es la de considerar a la libertad como un valor agregativo, en vez de uno esencialmente distributivo e individualizable. ${ }^{30}$ Esta idea permitiría evaluar el grado de libertad de una sociedad con pres-

\footnotetext{
${ }^{29}$ Scheffler, "What is Egalitarianism?”.

${ }^{30}$ La visión de Carlos Nino, en Etica y Derechos Humanos (Paidós, 1984) según la cual la autonomía es un valor agregativo, merece también esta crítica.
} 
cindencia de su distribución. Así, sería en principio posible afirmar que en el Chile de Pinochet había más libertad que en el Chile de hoy, si fuera cierto (lo cual no es del todo implausible) que Pinochet y su gobierno disfrutaban de mayor capacidad de acción que el conjunto de la sociedad chilena actual. Esto es absurdo. Por supuesto, nunca podría afirmarse esta idea si se entendiera la libertad como propongo (como la vigencia de los derechos democrático-constitucionales). Pero aun si se basara en la idea más abstracta de autonomía, resultaría un uso demasiado elástico de dicha noción aplicarla a la situación en que una persona o sub-grupo social acumula mayor poder que el que, en otra situación, disfruta el conjunto de la sociedad de manera menos concentrada. La primer situación no es un caso de autonomía, sino de heteronomía extrema.

La segunda idea errónea es la que juzga los avances o retrocesos en términos de libertad enfocándose en la capacidad de acción de algunos miembros de la sociedad, y no de todos. Aquí, el error no consiste en concebir a la libertad agregativamente, ya que la postura toma como criterio el poder de ciertos individuos. El problema, antes bien, es uno de falta de imparcialidad. Así, se acusa a las políticas igualitarias de afectar la libertad, porque su vigencia disminuiría el menú de opciones de los mejor situados. La igualdad sería, en esta línea de pensamiento, demasiado “demandante”. ${ }^{31}$ Por supuesto, esta posición ignora que el status quo resulta a veces demasiado demandante respecto de los peor situados, a quienes se les requiere, irrazonablemente, que presten obediencia a un orden jurídico-político que les niega a ellos el acceso a las libertades que otros tienen garantizado.

Podría objetárseme que al entender la libertad como el conjunto de derechos constitucionales modernos, estoy inclinando la balanza hacia el lado de la igualdad, ya que los derechos democráticos son igualitarios por definición, porque se reconocen respecto de todos por igual, y derivan del reconocimiento de la igualdad moral básica de las personas. Eso es cierto, pero no veo que exista una alternativa mejor: la idea de la libertad como margen de acción, como un estándar agregativo, o como el conjunto de opciones de los más aventajados, ciertamente, no parecen ser versiones más aceptables. La primera versión (según la cual deberíamos hablar de la "libertad" de torturar) no alcanza siquiera a denotar un valor; la segunda (que nos llevaría a elogiar la libertad de Chile bajo Pinochet) o bien colapsa en la primera, o bien es incompatible con una reconstrucción razonable de la noción de autonomía, que es la base sobre la que suele fundamentarse. Por

\footnotetext{
${ }^{31}$ La preocupación acerca del carácter demandante de la justicia (en su versión utilitarista, igualitaria, o en otras) no se limita al terreno de la libertad.
} 
último, la tercera versión, ni siquiera supera el filtro de la mínima imparcialidad requerida por la deliberación moral y política.

Tal parece, pues, que la persistencia en la cultura moderna de la idea de un conflicto irresoluble entre la igualdad y la libertad es un residuo filosófico de la guerra fría.

\section{Igualdad y Envidia}

"La envidia era una vez considerada uno de los siete pecados capitales, antes de que se convirtiera en una de las más admiradas virtudes, bajo su nuevo nombre, 'justicia social., "32

Enfoquémonos ahora en el tercer nivel de la moralidad: las virtudes. No sólo se dice de la igualdad que trunca el progreso económico, perjudicando a algunos sin beneficiar a nadie, y que es incompatible con la libertad o viola derechos. Además, se la suele considerar un falso ideal que emana de uno de los peores vicios: la envidia. La creencia en la igualdad encubriría, o racionalizaría, para estos críticos, la envidia de quienes sienten que fracasaron en la vida hacia los miembros exitosos de la sociedad. Esta es la objeción más importante que vincula la igualdad con la envidia. Otras objeciones al igualitarismo que están centradas en el concepto de envidia, dicen que los igualitarios tienen la utópica esperanza de eliminar la envidia de la lista de disposiciones humanas, ignorando de este modo que ciertos trazos de la naturaleza humana y social no resultan modificables. Finalmente, algunos autores conservadores sugieren que las instituciones y políticas igualitarias, aparte de ser el resultado de impulsos envidiosos, refuerzan el nivel de envidia social existente.

\section{1. ¿Está el igualitarismo basado en la envidia?}

Una distinción puede ayudar a entender mejor este problema. Al menos dos preferencias diferentes pueden ser consideradas como preferencias envidiosas:

I. A envidia a B si quiere algo que B tiene.

II. A envidia a B si quiere que B cese de tener algo, sin necesariamente desearlo para sí.

En el caso I, A quiere mejorar su posición. El empeoramiento en la situación de $\mathrm{B}$ (que resultaría si la única forma de que A obtuviera el estatus de $B$ fuera a través de una redistribución de $\mathrm{B}$ a $\mathrm{A}$ ) es querido solo como medio para lograr ese fin. En el caso II, A solamente quiere que B no esté

32 Thomas Sowell, The Quest for Cosmic Justice, (The Free Press: New York, 1999), p. 77 
mejor que él. Su objetivo es que B resulte nivelado hacia abajo (hacia la situación de A).

El primer tipo de preferencia no es puramente externa, ya que no se refiere exclusivamente a otros. La segunda es puramente externa, ya que tiene como objeto el bienestar o los recursos de un tercero. A los efectos de nuestra discusión, es conveniente dejar de lado el primer tipo de envidia, por su carácter inofensivo. Una importante característica de la envidia en el sentido en el que figura en la objeción que estoy analizando es que ella es una disposición cuestionable. La preferencia I no tiene nada de impugnable. Dentro de esta categoría entra el uso de la palabra envidia como un mero recurso técnico, sin connotaciones morales. En este sentido, decimos que A envidia a B si preferiría tener la canasta de bienes de B, a su propia canasta. Creo que esta envidia técnica no les provee ningún argumento a los anti-igualitarios. Supóngase que A desea tener cierto activo poseído por B. Tal preferencia desnuda no es envidiosa, en el sentido "duro" de envidia. De hecho, este tipo de preferencia es lo que hace posible buena parte de las instituciones sociales. Después de todo, la propia práctica del comercio está basada en la existencia y satisfacción de este tipo de deseos. A quiere las manzanas de B, $\mathrm{B}$ quiere tener las peras de A, $\mathrm{y}$, estas preferencias posibilitan un intercambio que hace que los dos se hallen mejor. Cuando los economistas hablan de la envidia como el mero deseo de los bienes o canasta de bienes de otros, se están refiriendo a este fenómeno, moralmente inocuo.

Así, por ejemplo, el término "envidia" es usado como una prueba de la aceptabilidad de la distribución inicial de recursos en la teoría de Dworkin. ${ }^{33}$ El criterio de diversidad no-dominada propuesto por Philippe Van Parijs (inspirado en la teoría de Bruce Ackerman) como un modo de neutralizar las diferencias de cualidades internas es definido por este autor como "potencialmente libre-de-envidia". ${ }^{34}$ John Roemer describe como "equitativa" una asignación de bienes “sí, y sólo sí, ningún individuo ‘envidia’ a otro”, un criterio compartido por muchos economistas desde $1950 .^{35}$

Cuando Elizabeth Anderson inicia su vigoroso ataque al "igualitarismo de la suerte" expone un listado de algunas de las afirmaciones supuestamente contraintuitivas de los autores de esta escuela, y entre ellas, considera que este uso de la noción de envidia "alimenta la sospecha de que el motivo

${ }^{33}$ Ronald Dworkin, “What is Equality? Part 2: Equality of Resources”, Philosophy and Public Affairs 10, N. 4, 1981, P. 285.

${ }^{34}$ Philippe Van Parijs, Real Freedom for All, (Oxford University Press, 1995), p. 87. [NT: Hay versión en castellano, Libertad Real para Todos, Ed. Paidós]

${ }^{35}$ El criterio y sus antecedentes históricos son explicados en John E. Roemer, Theories of Distributive Justice, (Harvard University Press, 1996), pp. 317-322. 
detrás de las políticas igualitarias es la mera envidia." ${ }^{36}$ Pero existe una diferencia importante entre "alimentar una sospecha" y cometer un error de importancia filosófica. El uso del término “envidia” puede ser criticado a causa de la resonancia normativamente negativa de tal término. Esta es, en mi opinión, una objeción plausible, pero difícilmente constituye una objeción sustantiva, una vez que se aclara el sentido inofensivo en el que la idea de envidia está siendo usada. El meramente querer tener alguna cosa de otros no equivale a ser envidioso en el sentido de manifestar una disposición moralmente objetable. Por lo tanto, para que la objeción de que la igualdad expresa envidia sea relevante, debemos entender a la envidia en un sentido moralmente significativo. Si no, la objeción no sería tal, es decir, no consistiría en enrostrar un defecto o falla moral.

De todas formas, si se entendiera que la envidia que se enrostra al igualitarismo es la descripta en la versión I la objeción sería fácilmente contestable. Supóngase que el igualitario es acusado de envidioso en el sentido de legitimar el deseo de los peor situados de los bienes o ventajas ajenas. La respuesta a esta acusación es que el igualitarismo no acepta que dichos bienes o ventajas sean, en verdad, “ajenos”. Del mismo modo en que el deseo de que algo robado nos sea devuelto no implica que envidiemos al ladrón, la afirmación de que los recursos sociales deben ser redistribuidos no implica cobijar (ni precisa estar respaldado por) un sentimiento de envidia hacia los más aventajados. La envidia en el primer sentido que describí es el deseo de algo ajeno sin otra razón o motivo. Cuando existe un motivo o razón legítima para desear lo que otros poseen, la envidia se torna irrelevante. El anti-igualitarismo presupone lo que quiere demostrar al acusar a la igualdad de ser un ideal basado en la envidia. Lo que presupone es que la igualdad no provee ninguna razón legítima para la redistribución. Al no haber ninguna razón que la respalde, el anti-igualitario recurre a la noción de envidia, como un modo de denunciar la falta de legitimidad del igualitarismo. Pero, al igual que la persona que exige la devolución de lo robado, quien demanda igualdad en la distribución de recursos y oportunidades está reclamando algo que considera propio, no ajeno y tiene a su disposición razones suficientes para sustentar su reclamo: un esquema institucional que ampara fuertes disparidades materiales implica un mensaje descalificador respecto de los más desafortunados, a quienes el estado dispensa menos respeto que a los más aventajados.

He dicho que debemos entender a la envidia en la versión II (A envidia a B si quiere que B cese de tener algo, sin necesariamente desearlo para sí).

${ }^{36}$ Elizabeth S. Anderson, "What is the Point of Equality?”, Ethics 109, (January 1999), 287-337, p. 287. 
Ahora bien, ¿qué hay de malo en la envidia en esta segunda versión? Algunos consideran a la envidia como una disposición humana inevitable. Si esto fuera cierto, luego, ese hecho podría dejar muy poco espacio para la evaluación moral de una persona envidiosa. Pero todavía podría ser posible decir algo desde la perspectiva moral. Sería como la evaluación moral de una supuesta disposición al racismo. Aun si fuera verdad que los humanos tienen una propensión natural a evitar a las personas de otros orígenes étnicos, esto no precluiría la condena moral del racismo. La erradicación del racismo resultaría más dificultosa, pero no menos urgente. Si confiamos, contra Hume, en que la razón puede controlar (al menos en parte) a las pasiones, luego no veo un problema en depender de una concepción más o menos moralizada de la envidia, una concepción que incorpore elementos normativos. Esta no es la ruta favorecida por Rawls, quien explícitamente rechaza considerar la envidia como un sentimiento moral, porque, según él, "no es necesario citar ningún principio moral en su explicación" ${ }^{37}$. Por mi parte, pienso que la envidia puede ser objetada en base a, al menos, dos consideraciones. En primer lugar, una persona envidiosa puede ser vista como estando en falta en relación con la responsabilidad indelegable sobre su propia vida. Una persona envidiosa no está prestando atención a lo que constituye su particular desafío, a saber, conducir su propia vida. En cambio, dedica una atención desmesurada a la situación de otras personas. La sociabilidad es un hecho de la naturaleza humana, y ello implica que vivimos haciendo comparaciones sobre cómo otros resuelven problemas similares a aquellos que nosotros enfrentamos, que tratamos de tomar ventaja de la experiencia de personas que conocemos, etc. Una persona sociable, no-envidiosa vive con un ojo puesto en las vidas de otros, pero la persona envidiosa viven con los dos ojos puestos sobre las vidas de otras personas. ${ }^{38}$ Esta concepción de la envidia no la considera como una característica dada, no modificable de la naturaleza humana, sino como una falta ética, a saber, una fracaso en hacer frente a la especial responsabilidad sobre nuestro propio destino, una propensión que resta valor a nuestras vidas. 481]

${ }^{37}$ J. Rawls, A Theory of Justice, p. 533. [J. Rawls, Teoría de la Justicia, Ed. F.C.E., página

${ }^{38}$ Frankfurt, en The Importance of What We Care About., Cambridge University Press, 1988, p. 136, habla en estos términos cuando descalifica al igualitarismo económico: "Un interés por la igualdad económica, construida como deseable en sí misma, tiende a a desviar la atención de las personas del esfuerzo por descubir -dentro de su experiencia de sí mismo y de su vida- lo que a él mismo realmente le importa y lo que verdaderamente lo satisfase, aunque esta es la más básica y la más decisiva tarea, de la cual depende una selección inteligente de objetivos económicos. Exagerar la importancia moral de la igualdad económica es dañoso, en otras palabras, porque es alienante.” (Énfásis añadido). 
En segundo lugar podemos aplicar a la envidia las mismas impugnaciones que fueron dirigidas a la nivelación hacia abajo, ya que ese es, precisamente, el contenido de la preferencia envidiosa. Si la primer objeción es interna, y se mueve en la dimensión de las virtudes, esta segunda crítica sobrepasa esa dimensión, ya que cuestiona a la envidia como un antecedente espurio respecto de la organización institucional y las políticas públicas. La preferencia de que nadie tenga nada que no tengan los demás queda descalificada por implicar una preferencia a favor de la nivelación hacia abajo, es decir, un deseo de empeorar la situación de algunos sin razón ni beneficio alguno.

Parentéticamente, quisiera señalar que mientras muchos autores antiigualitarios se ocupan negativamente de la envidia, parecen aceptar su exacto reverso, ${ }^{39}$ el deseo de ser envidiado por otros. Este deseo es uno muy común, y publicitarios y expertos en marketing usualmente toman ventaja de la existencia de esta propensión. La envidia sería un mal sentimiento, propio de los igualitarios, en tanto que el deseo de ser envidiado sería un sentimiento positivo, un motor del progreso económico. Considérense las siguientes palabras de Schoek: "Sólo cuando un hombre comprende la futilidad de dar vueltas en comparaciones envidiosas entre su propia suerte y la de otros, cuando una persona comprende que la tormenta de la envidia es ineludible porque nunca carece de estímulo, y, aparte de esta comprensión, es capaz de modificar este sentimiento de envidia en un impulso agonístico, esforzándose para 'superar' los logros de otros, alcanza, por su intención aunque motivado por la envidia, un fundamentalmente nuevo plano de aumentode-valor: la conducta competitiva." ${ }^{40}$ En esta visión asimétrica habría, pues, una envidia mala, la de los igualitarios, y un impulso a provocar la envidia ajena que sería bueno. A este impulso positivo se lo llama competitividad. Esta asimetría es inconsistente. Esta preferencia de ser envidiado por otros resulta moralmente objetable por dos cuestiones. Primero, simplemente porque tiene como objetivo provocar (y entonces es moralmente parasitaria de) un sentimiento vicioso: la envidia. Segundo, y mucho más importante, porque comparte con la actitud de la envidia el mismo desprecio hacia el principio de la especial responsabilidad sobre la propia vida. La persona que construye su vida pensando primariamente acerca de la envidia que sus logros suscitarán en otras, se halla, en el mismo grado que la persona envi-

${ }^{39}$ J. Rawls, op. cit., p. 533, también se refiere a un sentimiento reprobable y relacionado a la envidia, "grudgingness", que consiste en desear que quienes están en una posición inferior, no alcancen nuestra posición.

${ }^{40}$ Schoeck, H., op. cit., p. 416-417. [Hay versión castellana, Helmutt Schoeck, La Envidia y la Sociedad, Unión Editorial S.A., Madrid] 
diosa, fracasando en situar su vida en el centro de su atención, y tomando a los demás como medios y no como fines en sí mismos. El punto es que cualquier consideración aceptable de la envidia debe incluir una condena simétrica de su reverso. El deseo de ser objeto de la envidia de otros se halla, con la actitud de la envidia, en la misma barca moral.

\section{2. ¿Causa envidia la igualdad?}

Existe un segundo nivel en el que se suele vincular al igualitarismo con la envidia. Esta objeción consiste en afirmar que las instituciones propias de un sistema igualitario incrementarían la envidia. Esta idea fue expuesta, por ejemplo, por Nozick, ${ }^{41}$ quien conecta la envidia con la autoestima. Las personas, según Nozick, evalúan sus logros en ciertas esferas de la vida comparando sus logros con los logros ajenos. Cuando su puntaje baja en varias (para ellos) esferas significativas, eso afecta su autoestima y se vuelven envidiosas. El problema con el igualitarismo, dice Nozick, es que tiende a "reducir...el número de dimensiones diferenciadoras". En consecuencia, sería más difícil para cada individuo usar una "estrategia de sopesamiento no uniforme que dé mayor peso a la dimensión en la cual su calificación es más alta." Por el contrario, Rawls adopta una visión optimista de la influencia de las instituciones igualitarias en el problema de la envidia. ${ }^{42}$ Las razones que suministra son las siguientes. Primero, la confianza en las instituciones igualitarias limitaría las disparidades de bienestar. Segundo, contrariamente a Nozick, él cree que el tipo de sociedad igualitaria que está defendiendo impulsaría el florecimiento de muchas asociaciones, que dividiría a la sociedad en "muchos grupos no comparables". Esto, a su turno, tiende a "reducir la visibilidad”, "de las variaciones en las perspectivas de los hombres".

Resulta interesante que ambos autores parten de una caracterización completamente diferente de la sociedad igualitaria en cuanto a la diversidad de modos de vida. Nozick afirma que el igualitarismo disminuiría el número de dimensiones a lo largo de las cuales las personas podrían compararse con otras. Rawls sostiene que, bajo un orden igualitario, numerosas asociaciones florecerían, y de acuerdo a ello, sería más complicado para las personas efectuar comparaciones envidiosas. A mi juicio, el problema con el argumento de Nozick es que se encuentra basado sobre una descripción distorsionada del igualitarismo. El igualitarismo no tiene como propósito crear una sociedad donde todos usen la misma ropa, coman la misma comida, lean los mismos libros, y así sucesivamente. El igualitarismo no condena la diversidad, sino que trata de suministrarle fundamentos más sólidos, dando

\footnotetext{
${ }^{41}$ Op. cit., p. 245.

${ }^{42}$ TJR, pp. 468-74.
} 
a todos y cada uno iguales oportunidades y recursos para disfrutar de esa posibilidad de vivir vidas diversas.

\section{Conclusión}

El ideal de la igualdad es atacado por favorecer el empeoramiento en la situación de algunas personas sin que nadie más se beneficie, por conculcar derechos y libertades, y por estar basado en (y reforzar) sentimientos envidiosos. Algunos de estos ataques han ganado credibilidad debido a la desafortunada estrategia seguida por muchos igualitarios frente a estas objeciones. La estrategia ha sido la de aceptar que el igualitarismo propende a nivelar para abajo (lo que implica tácitamente aceptar la asimilación de igualdad y envidia) o a conflictuar con la libertad. En estas líneas he intentado una respuesta diferente, basada en una interpretación del valor de la igualdad según la cual éste es un ideal que no requiere sino que rechaza nivelar para abajo, que no resulta en la vulneración de los derechos sino que provee su fundamento más sólido, y que no está respaldado por sentimientos de envidia. Si no estoy equivocado, pues, buena parte del discurso en contra de la igualdad, y de los temores que genera, están basados en una visión deformada de este valor, y no en interpretaciones mínimamente plausibles.

Mi enfoque presupone una actitud monista, y debo decir algo en defensa de esta actitud, según la cual la igualdad es la igualdad de las personas libres, del mismo modo que la libertad que cuenta es la igual libertad. No me atrevo a negar que la visión pluralista pueda ser, en última instancia, verdadera. Lo que parece objetable, empero, es la ferviente convicción en que los valores fundamentales están en conflicto, en lugar de simplemente aseverar la posibilidad de ese choque. Los pluralistas acusan a aquellos que niegan la existencia de disonancia entre valores de ser dogmáticos, pero la acusación puede ser redirigida contra los pluralistas. ¿Cómo podemos justificar la convicción “a priori” de que los valores están en conflicto?

Es importante tener en mente que en el terreno de la filosofía política, la fuerza del desafío que plantea el pluralismo no radica en la idea de conflicto, sino en la idea de que esos conflictos son inerradicables. La amenaza es la idea de la imposibilidad de acomodar de un modo razonable los ideales en aparente conflicto, no la mera idea del conflicto. ${ }^{43}$ El problema, para las democracias modernas, no es la afirmación de que hay ideales valiosos en tensión, sino la afirmación de que no hay modos aceptables de canalizar esas tensiones. El desafío es responder a la idea de que hagamos lo que hagamos

\footnotetext{
${ }^{43}$ Cfr., la contribución de Thomas Nagel en el libro The Legacy of Isaiah Berlin, Editado por Mark Lilla y Ronald Dworkin (New York Review of Books, 2002).
} 
estamos perdidos, porque todas las alternativas implican violencia, arbitrariedad, o la victimización injusta de algunos.

A veces se presenta al pluralismo como una visión austera y no pretenciosa en relación al poder de la razón. La idea es que sería muy ambicioso afirmar que es posible alcanzar una armonía entre los valores, sin ningún sacrificio ni residuo moral. El monismo sería, a los ojos de esta crítica, una postura infantil e irrealista, que desconoce el aspecto trágico de la vida, y que solamente puede basarse en una concepción todopoderosa de la razón. Mi perspectiva es que en el estado aún subdesarrollado en que se encuentra la discusión de los problemas morales, resulta tan pretencioso afirmar la armonía, como afimar lo contrario, es decir la existencia del conflicto irremediable de los valores. Afirmar a priori que no hay, ni habrá jamás, un modo de compatibilizar valores aparentemente en pugna también aparece como un ejercicio soberbio (y por tanto, paradójicamente, irracional) de la razón, y una convicción al menos prematura, con el agravante de que ocupa un rol obturador de la deliberación, al descalificar de entrada todo intento de lograr una convivencia aceptable entre distintos ideales.

¿Quién le teme a la igualdad? Quienes la confunden con la caricatura construida por sus adversarios. 